extrinsic and intrinsic cases tested with house dust, pollens, and Aspergillus fumigatus antigens (Bencard) showed appreciable sensitization in extrinsic asthma but gave values compatible

TABLE I-Lymphocyte Sensitization to Antigens in Patients Suffering from Intrinsic and Extrinsic Asthma and in Normal Control Subjects Expressed as Percentage Slowing in the Macrophage Electrophoretic Mobility Test

\begin{tabular}{|c|c|c|c|c|c|c|c|}
\hline $\begin{array}{l}\text { Case } \\
\text { No. }\end{array}$ & Sex and Age & $\begin{array}{c}\text { Encepha- } \\
\text { litogenic } \\
\text { Factor }\end{array}$ & $\underset{\text { Test }}{\text { Kveim }}$ & BSA & $\begin{array}{c}\text { Egg } \\
\text { Albumen }\end{array}$ & Muscle & $\begin{array}{c}\text { Purified } \\
\text { Protein } \\
\text { Derivative }\end{array}$ \\
\hline $\begin{array}{c}\text { Intrinsic: } \\
1 \\
2 \\
3 \\
4 \\
5 \\
6 \\
7 \\
8 \\
9 \\
10 \\
11 \\
12 \\
13 \\
14 \\
15\end{array}$ & $\begin{array}{ll}\text { F. } & 42 \\
\text { F. } & 59 \\
\text { F. } & 53 \\
\text { F. } & 43 \\
\text { M. } & 64 \\
\text { M. } & 46 \\
\text { F. } & 40 \\
\text { F. } & 39 \\
\text { F. } & 35 \\
\text { F. } & 54 \\
\text { F. } & 62 \\
\text { M. } & 60 \\
\text { F. } & 60 \\
\text { F. } & 46 \\
\text { F. } & 46\end{array}$ & $\begin{array}{r}14.6 \\
13.0 \\
14.5 \\
13.6 \\
11.3 \\
11.2 \\
11.2 \\
8.2 \\
11.6 \\
10.5 \\
9.8 \\
11.5 \\
12.8 \\
12.3 \\
11.0\end{array}$ & $\begin{array}{l}6 \cdot 9 \\
9 \cdot 7 \\
9 \cdot 3 \\
8 \cdot 6 \\
5 \cdot 6 \\
6 \cdot 2 \\
5 \cdot 5 \\
8 \cdot 6 \\
6 \cdot 3 \\
7 \cdot 1 \\
6 \cdot 8 \\
8 \cdot 0 \\
= \\
=\end{array}$ & $\begin{array}{l}6 \cdot 9 \\
9 \cdot 2 \\
8 \cdot 4 \\
7 \cdot 5 \\
4 \cdot 8 \\
6 \cdot 1 \\
5 \cdot 7 \\
2 \cdot 9 \\
6 \cdot 7 \\
7 \cdot 5 \\
6 \cdot 5 \\
6 \cdot 1 \\
4 \cdot 4 \\
4 \cdot 7 \\
4.9\end{array}$ & $\begin{array}{l}7 \cdot 9 \\
8 \cdot 6 \\
7 \cdot 0 \\
4 \cdot 2 \\
5 \cdot 9 \\
5 \cdot 2 \\
2 \cdot 9 \\
6 \cdot 6 \\
9 \cdot 2 \\
7 \cdot 5 \\
2 \cdot 7 \\
4 \cdot 5 \\
4 \cdot 5 \\
5 \cdot 2\end{array}$ & $\begin{array}{l}\bar{Z} \\
8 \cdot 3 \\
\bar{Z} \\
6 \cdot 2 \\
6 \cdot 3 \\
5 \cdot 5 \\
7 \cdot 1 \\
8 \cdot 2 \\
8 \cdot 0 \\
9 \cdot 4 \\
5 \cdot 5 \\
5 \cdot 1 \\
5.9\end{array}$ & $\begin{array}{l}15 \cdot 4 \\
16 \cdot 7 \\
17 \cdot 7 \\
14 \cdot 6 \\
15 \cdot 1 \\
15 \cdot 8 \\
15 \cdot 1 \\
13 \cdot 4 \\
17 \cdot 1 \\
17 \cdot 1 \\
16 \cdot 0 \\
18 \cdot 0 \\
= \\
=\end{array}$ \\
\hline $\begin{array}{c}\text { Extrinsic: } \\
16 \\
17 \\
18 \\
19 \\
20 \\
21 \\
22 \\
23 \\
24 \\
25 \\
26\end{array}$ & $\begin{array}{ll}\text { F. } & 22 \\
\text { F. } & 35 \\
\text { M. } & 47 \\
\text { M. } & 34 \\
\text { M. } & 44 \\
\text { F. } & 43 \\
\text { F. } & 24 \\
\text { M. } & 13 \\
\text { M. } & 34 \\
\text { F. } & 42 \\
\text { M. } & 55\end{array}$ & $\begin{array}{l}2.9 \\
9.1 \\
3.4 \\
5.1 \\
1.9 \\
4.4 \\
6.2 \\
5.3 \\
2.3 \\
1.7 \\
1.3\end{array}$ & $\begin{array}{l}1 \cdot 8 \\
6 \cdot 3 \\
1 \cdot 9 \\
2 \cdot 9 \\
2 \cdot 2 \\
0 \cdot 1 \\
2 \cdot 7 \\
3 \cdot 6 \\
2 \cdot 3 \\
0 \cdot 6 \\
1 \cdot 4\end{array}$ & $\begin{array}{l}\overline{6.5} \\
2.3 \\
2.8 \\
2.3 \\
1.8 \\
3.4 \\
1.8 \\
1.2 \\
1.7 \\
1.5\end{array}$ & $\begin{array}{l}2.3 \\
5.9 \\
1.9 \\
2.8 \\
0.9 \\
1.0 \\
1.4 \\
3.1 \\
1.5 \\
2 \cdot 2 \\
0.8\end{array}$ & $\begin{array}{l}1.4 \\
6.3 \\
2.0 \\
2.9 \\
1.9 \\
1.3 \\
2.5 \\
1.9 \\
3.0 \\
1.9 \\
0.2\end{array}$ & $\begin{array}{l}17 \cdot 9 \\
16 \cdot 0 \\
16 \cdot 5 \\
15 \cdot 9 \\
16 \cdot 1 \\
18 \cdot 4 \\
16 \cdot 0 \\
17 \cdot 6 \\
16 \cdot 9 \\
16 \cdot 4 \\
17 \cdot 4\end{array}$ \\
\hline $\begin{array}{l}\text { Normal } \\
\text { Subjects } \\
\text { (mean) }\end{array}$ & & $\begin{array}{c}1.4 \\
(45)\end{array}$ & $\begin{array}{l}1.5 \\
(15)\end{array}$ & $\begin{array}{l}1 \cdot 1 \\
(70)\end{array}$ & $\begin{array}{l}1 \cdot 1 \\
(27)\end{array}$ & $\begin{array}{l}1.5 \\
(28)\end{array}$ & $15-20$ \\
\hline
\end{tabular}

TABLE II-Lymphocyte Sensitization to House Dust, Pollen, and Aspergillus Skin Test Antigens in Intrinsic and Extrinsic Asthma Expressed as Percentage Slowing in the Test

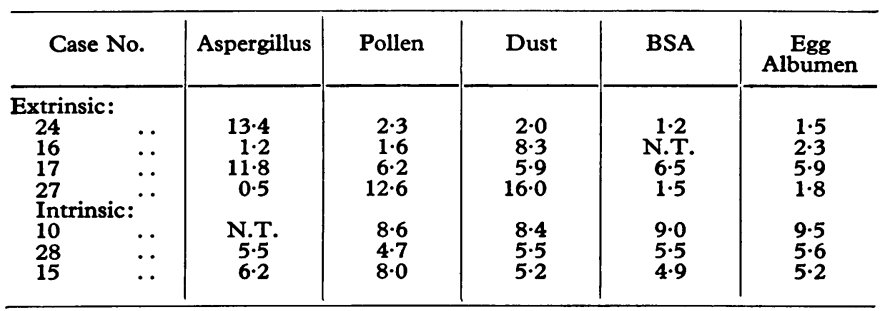

N.T. $=$ Not tested. with those obtained for non-specific antigens-for example, egg, BSA, etc.-in intrinsic disease (table 2). Some of the skin test antigens, however, showed inherent toxicity in our test system and would require further purification to confirm these results.

\section{Discussion}

The general picture of immune sensitization in asthma shows a clear division into two groups corresponding to a clinical classification of extrinsic and intrinsic disease, including a few extrinsic cases showing some element of intrinsic disease. The classical extrinsic asthma cases showed pronounced lymphocyte sensitization to the antigen inducing their disease, but little sensitization to a battery of other antigens. On the other hand, intrinsic asthma showed noticeable sensitization to the same battery of antigens without specificity to any particular one. These findings suggest that intrinsic disease is a disorder of general immunity, while the extrinsic form appears as a predominantly specific sensitization. The immunological evidence of Hall et al. (1966) and Turner-Warwick and Haslam (1970) also points in the same direction.

Clinical evidence in intrinsic asthma also suggests a defect of general immunity. In two patients the onset of asthma coincided with the onset of rheumatoid disease, and a further two patients developed severe polyarthritis, in one accompanied by erythema nodosum, after a change in therapy from oral steroid to topical beclomethasone. The changes after alteration in therapy could, alternatively, have resulted from the withdrawal of systemic steroid as described by others.

\section{References}

Caspary, E. A. (1971). Nature Nerw Biology, 231, 24.

Caspary, E. A. (1972). Clinical and Experimental Immunology, 11, 305. Caspary, E. A., and Field, E. J. (1965). Proceedings of the New York Academy of Sciences, 122, 182.

Caspary, E. A., and Field, E. J. (1971). British Medical fournal, 2, 613.

CIBA Foundation Symposium (1971). Identification of Asthma, No. 38. London, Churchill.

Field, E. J., and Caspary, E. A. (1971). Fournal of Clinical Pathology, 24, 179. Hall, R., Turner-Warwick, M., and Doniach, D. (1966). Clinical and Experimental Immunology 1, 285.

Hughes, D., and Caspary, E. A. (1970). International Archives of Allergy, 37, 506.

Turner-Warwick, M., and Haslam, P. (1970). Clinical and Experimental Immunology, 7, 31 .

\title{
Immunological Studies in Ugandan Patients with Hepatocellular Carcinoma
}

\author{
ARON PRIMACK，CHARLES L. VOGEL， LEWELLYS F. BARKER
}

British Medical fournal, 1973, 1, 16-19

\section{Summary}

Immunological studies were performed on Ugandan patients with hepatocellular carcinoma to test the hypothesis that the high rate of persistence of hepatitisassociated antigen in these patients is the result of defects in host immune response. The responses to 1-chloro-

Uganda Cancer Institute, Kampala, Uganda

CHARLES L. VOGEL, M.D., Director, Solid Tumour Centre

Bureau of Biologics, Food and Drug Administration, Rockville, Maryland, U.S.A.

LEWELLYS F. BARKER, M.D., Division of Virology 2,4-dinitrobenzene sensitization and to a battery of recall skin test antigens were normal, as was the humoral antibody response to tularaemia antigen. Neither hypogammaglobulinaemia nor specific immunoglobulin deficiencies were found. Thus it appears unlikely that generalized defects in host immune responses can account for the high incidence of persistent hepatitis $B$ virus infection found in Ugandan patients with hepatocellular carcinoma.

\section{Introduction}

Hepatitis-associated antigen (H.A.A., hepatitis B antigen, Australia antigen) is found persistently in the blood of $40 \%$ of 
Ugandan patients with hepatocellular carcinoma but in only 3\% of control subjects (Vogel et al., 1970, 1972). Further refinements of technique (radioimmunoassay) have increased the proportion of seropositive patients to $55 \%$ (unpublished data). A similarly significant association between H.A.A. and hepatocellular carcinoma has been found in many other areas of the world (Okochi and Murakami, 1968; Hadziyaunis et al., 1970; Prince, et al., 1970; Sherlock, et al., 1970; Anand and Malaviya, 1971; Bagshawe et al., 1971; Denison, et al., 1971; Terés et al., 1971; Tong et al., 1971; Simons, 1972, personal communication), although apparently conflicting reports have also appeared (Smith and Blumberg, 1969; Wright et al., 1969; Alpert and Isselbacher, 1971; Welsh et al., 1972). While it seems plausible that chronic infection with hepatitis B virus might play a part in the aetiology of this disease, other possible explanations exist. In other diseases, such as some leukaemias and lymphomas, Down's syndrome, lepromatous leprosy, and uraemia, host immunological deficiencies have been invoked to explain the high incidence of persistent hepatitis B virus infection (Miller, 1962; Wilson et al., 1965; Waldorf, et al., 1966; Sutnick et al., 1969). The present study was carried out to test the hypothesis that host immunological deficiencies might explain the association between persistence of H.A.A. and hepatocellular carcinoma in Uganda.

\section{Patients and Methods}

Forty-nine consecutive Ugandan African patients with biopsyproved hepatocellular carcinoma in whom the presence or absence of concomitant cirrhosis was known and who were admitted between December 1969 and March 1972 to the Solid Tumour Centre of the Uganda Cancer Institute were studied for the presence of H.A.A. and of antibody to H.A.A. (antiH.A.A.). On 16 of these patients, admitted between October 1971 and March, 1972, more extensive immunological studies were performed after their informed consent had been obtained.

Initial evaluation of the patients included a complete clinical history, physical examination, complete blood count, liver function studies including serum total bilirubin, aspartate aminotransferase, and alkaline phosphatase estimations, radiography of the chest, lumbosacral spine, and any painful bones, colloidal gold liver scan, needle or open liver biopsy, and diagnostic paracentesis. On the basis of these investigations the patients were classified according to a modification (summarized in table $\mathrm{I}$ ) of a recently described staging scheme (Vogel and Linsell, 1972).

TABLE I-Modified Staging Scheme for Hepatocellular Carcinoma

\begin{tabular}{l|l}
\hline Stage & Characteristics \\
\cline { 2 - 3 } I* $^{*}$ & $\begin{array}{l}\text { No ascites, cachexia, or evidence of portal hypertension, total serum } \\
\text { bilirubin }<2.0 \mathrm{mg} / 100 \mathrm{ml}\end{array}$ \\
II* & $\begin{array}{c}\text { Ascites or cachexia present but no evidence of portal hypertension and } \\
\text { total serum bilirubin }<2.0 \mathrm{mg} / 100 \mathrm{ml} \\
\text { Evidence of portal hypertension, actual or impending hepatic coma, } \\
\text { total serum bilirubin }>2.0 \mathrm{mg} / 100 \mathrm{ml}\end{array}$ \\
III* $^{*}$ &
\end{tabular}

* IA, IIA, and IIIA signify designated stage with associated metastatic disease.

In addition, immunoglobulin determinations were performed on serum from eight healthy Kampala residents, nine patients with miscellaneous non-malignant conditions but without cirrhosis, 10 patients with biopsy-proved cirrhosis without cancer, 18 patients with cancer of non-hepatic origin, and 10 patients with acute viral hepatitis.

\section{SERUM TESTING}

Initial and serial serum specimens from patients with hepatocellular carcinoma were tested for H.A.A. by radioimmunoassay using solid-phase techniques (Peterson et al., in press) and AusRIA (Abbott Laboratories), counterelectrophoresis (Gocke and Howe, 1970), and complement fixation (Shulman and Barker, 1969) and for anti-H.A.A. by passive hemagglutination (Vyas and Shulman, 1970). Patients were regarded as H.A.A. positive if $\mathbf{H}$.A.A. radioimmunoassay or counterelectrophoresis tests were positive or if they had a titre of $1 / 4$ or greater in the complement fixation test. Patients were regarded as anti-H.A.A. positive if the passive hemagglutination test was positive at a dilution of $1 / 4$ or greater. For alpha-fetoprotein a double diffusion test (Vogel et al., 1970) was used with commercially available reagents.

\section{IMMUNOLOGICAL TESTING}

Immunoglobulins.-Serum IgG, IgM, and IgA levels were determined by the techniques of Fahey and McKelvey (1965), using Hyland Immunoplates.

Cellular Reactivity.-Sixteen patients with hepatocellular carcinoma were topically sensitized to 1-chloro-2,4-dinitrobenzene (DNCB) and challenged 14 days later according to the technique of Brown et al. (1967). Intradermal skin tests with tuberculin purified protein derivative (P.P.D.) (intermediate test strength), streptokinase-streptodornase (Varidase, 1/50), mumps skin test antigen, and candidin (Dermatophytin " 0 " $1 / 100$ ) were used to determine reactivity to recall antigens. Induration $5 \mathrm{~mm}$ or more in diameter at 48 hours was considered to indicate a positive reaction.

Circulating Antibody Reactivity.-A subcutaneous injection of $1 \mathrm{ml}$ of Foshay tularaemia vaccine was given to 14 of these same 16 patients and serum hemagglutinating antibodies were measured weekly for four to six weeks (Wright and Feinberg, 1952).

\section{STATISTICS}

Statistical analyses were performed with the Mann-Whitney $U$ test unless otherwise stated.

\section{Results}

As shown in table $\mathrm{II}^{*}$, of the 49 patients with hepatocellular carcinoma, 26 had associated cirrhosis and 23 did not. The two groups were comparable with regard to age, sex, and incidence

TABLE II-Characteristics of 49 Patients with Hepatocellular Carcinoma

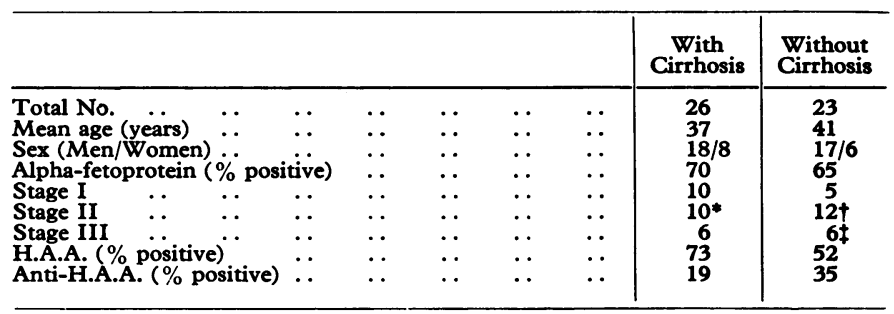

* Two with metastatic disease.

Three with metastatic disease

of alpha-fetoprotein. The groups were similar with regard to disease stage, although there was a slight preponderance of patients in stage $I$ in the group with cirrhosis.

\section{SERUM TESTING}

Nineteen $(73 \%)$ of the 26 patients with cirrhosis and $11(52 \%)$ of the 23 without had H.A.A. persisting over periods of at least

* A detailed list of results in individual patients is available from the authors on request. 
one month in serial specimens of serum. Five $(19 \%)$ of the patients with cirrhosis and eight $(35 \%)$ of those without were positive for anti-H.A.A. Differences in the incidence of H.A.A. and anti-H.A.A. between the two groups were not statistically significant by $\chi^{2}$ analysis. Among the 30 patients positive for H.A.A., five were also positive for anti-H.A.A.

\section{IMMUNOLOGICAL TESTING}

Immunoglobulins.-Serum IgG levels in the patients with hepatocellular carcinoma (table III) were not significantly different from those in the groups of control patients. All

TABLE III-Serum Immunoglobulin Levels $(\mathrm{Mg} / 100 \mathrm{ml})$ in Patients with Hepatocellular Carcinoma

\begin{tabular}{|c|c|c|c|c|c|c|c|}
\hline \multirow{2}{*}{\multicolumn{3}{|c|}{ Immunoglobulin }} & & \multicolumn{2}{|c|}{ With Cirrhosis $(n=26)$} & \multicolumn{2}{|c|}{ Without Cirrhosis $(n=23)$} \\
\hline & & & & Mean & Range & Mean & Range \\
\hline $\begin{array}{l}\text { IgG } \\
\text { IgM } \\
\text { IgA }\end{array}$ & $\begin{array}{l}\ldots \\
\ldots\end{array}$ & $\begin{array}{l}. \\
\cdots\end{array}$ & $\begin{array}{l}\ldots \\
\ldots\end{array}$ & $\begin{array}{r}2,600 \\
190 \\
432\end{array}$ & $\begin{array}{c}920-4,600 \\
54-780 \\
94-740\end{array}$ & $\begin{array}{r}2,765 \\
210 \\
380\end{array}$ & $\begin{array}{c}1,460-5,000 \\
46-700 \\
106-580\end{array}$ \\
\hline
\end{tabular}

patients, however, had higher levels than the eight healthy control subjects. Serum IgA and IgM levels in hepatocellular carcinoma patients with and without cirrhosis and in patients with cirrhosis alone were increased as compared with those in other control patients or healthy subjects $(P<0.05)$. No significant difference was found between hepatocellular carcinoma patients either with or without cirrhosis and patients with cirrhosis alone.

Cellular Reactivity.-All but one of the patients tested were sensitized to DNCB, a result comparable to that in a Ugandan control series (Ziegler et al., 1969), and all patients tested had positive skin reactions to at least two of the four recall antigens (table IV).

TABLE IV-Immunological Reactions of Patients with Hepatocellular Carcinoma

\begin{tabular}{|c|c|c|c|c|}
\hline \multirow{2}{*}{ Test } & \multicolumn{2}{|c|}{ With Cirrhosis $(n=26)$} & \multicolumn{2}{|c|}{ Without Cirrhosis $(n=23)$} \\
\hline & No. Tested & No. Positive & No. Tested & No. Positive \\
\hline $\begin{array}{l}\text { D.N.C.B. sensitization } \\
\text { Skin test a } \because{ }^{2} \quad \ldots \\
\text { Tularaemia antigen } \quad .\end{array}$ & $\begin{array}{l}7 \\
7 \\
7\end{array}$ & $\begin{array}{l}7 \\
7 * \\
7\end{array}$ & $\begin{array}{l}9 \\
9 \\
7\end{array}$ & $\begin{array}{l}8 \\
9 \\
6\end{array}$ \\
\hline
\end{tabular}

* Positive to two or more of P.P.D., streptokinase-streptodornase, mumps antigen, candidin.

Circulating Antibody Reactivity.-A humoral antibody response to tularaemia antigen was detected in all patients but one (table IV). This patient was the only one tested while receiving antineoplastic chemotherapy; he had received 1-(2chloroethyl)-3-cyclohexyl-1-nitrosourea (NSC-79037) 130 $\mathrm{mg} / \mathrm{m}^{2}$ body surface area orally six weeks before sensitization with tularaemia antigen. DNCB sensitization and response to recall skin test antigens were normal in this patient. The degree of antibody response in the remaining patients was similar to that reported for a series of Ugandan control subjects (Bluming et al., 1972).

\section{Discussion}

A simple association between persistent H.A.A. and a given disease does not necessarily imply an aetiological relationship. Host immunological deficiencies have been invoked to explain the persistence of H.A.A. in several diseases. Patients with Down's syndrome, for example, have impaired lymphocyte transformation in response to phytohaemagglutinin (Agarwaal et al., 1970), diminished responses to skin test antigens (A. I. Sutnick, unpublished), and low IgM levels (Sutnick, et al.,
1970). Patients with lepromatous leprosy have also been shown to have impaired cellular immune responses (Sutnick et al., 1969). Although it was initially thought that the increased incidence of H.A.A. in patients with various types of leukaemia was related to their high transfusion requirement, it has since been shown that H.A.A. is found more frequently in leukaemia than in non-leukaemic patients requiring multiple transfusions. In addition, patients with malignant diseases known to be associated with immunological defects, such as Hodgkin's disease, are more likely to be persistent H.A.A. carriers than patients with chronic myelogenous leukaemia, a disease in which most indices of immune function are normal (Sutnick et al., 1970).

The present study was designed to test the hypothesis that host immunological deficiencies might explain the significantly increased incidence of persistent H.A.A. in Ugandan patients with hepatocellular carcinoma. The data do not support such a hypothesis. Thus all but one of 16 patients tested were sensitized to DNCB and all responded to at least two of four recall skin test antigens. The single patient not responding to DNCB was not an H.A.A. carrier. Likewise, all patients but one showed humoral antibody responses to tularaemia antigen; the one patient failing to respond was the only patient in the study receiving antineoplastic chemotherapy at the time of testing. Finally, deficiencies of immunoglobulins were not encountered in patients with hepatocellular carcinoma. The previously reported finding of raised serum IgM and IgA levels in cirrhosis (Grabar, 1958) was confirmed in the present study, and similar levels were also found in patients with hepatocellular carcinoma without concomitant cirrhosis. Further studies on immunoglobulin levels in patients with various forms of liver disease in Uganda will appear in a separate report.

Thus it would appear that gross host immune deficiency as measured by the present methods is not responsible for persistence of H.A.A. in Ugandan patients with hepatocellular carcinoma. It remains possible, however, that a more specific immunological defect exists which permits the H.A.A. carrier state. Thus in the present series, although 30 patients were shown to have persistent H.A.A., only five $(16 \%)$ of these could be shown to be making specific antibody to H.A.A. The reasons for this apparent lack of antibody production in the face of a chronic antigenic challenge remain obscure.

One possible explanation is that the passive haemagglutination technique is not sensitive enough to detect low levels of antibody in the presence of excess antigen. This question may be resolved when more sensitive tests are used for the detection of antiH.A.A.

A second possibility is that antibody is bound in immune complexes in the presence of antigen excess. Planned studies of the complement system in Ugandan patients with hepatocellular carcinoma should help to resolve this question.

A third possibility is that these patients have a specific inability to respond with a normal antibody response to the chronic antigenic stimulus of H.A.A. A genetic susceptibility to H.A.A. persistence, which may be immunological in nature, has been postulated by Blumberg et al. (1969). Alternatively, it is possible that H.A.A. was acquired in utero or in infancy at a time when the patient was immunologically incompetent, resulting in specific immune tolerance to H.A.A. This possibility receives support from the findings of Schweitzer et al. (personal communication) who report chronic hepatitis B virus infection in infants born to mothers developing viral hepatitis during pregnancy. If a state of chronic hepatitis B antigenaemia was thus established early in life among some Ugandans there would be an opportunity for interaction with other common and potentially hepatotoxic environmental factors such as infantile malnutrition, aflatoxin contamination of food, and chronic parasitic infections. A combination of these factors, perhaps in a genetically susceptible host, might then lead to hepatic carcinogenesis.

Whether infection with hepatitis B virus plays any part in the aetiology of hepatocellular carcinoma in Ugandan patients remains speculative. The results of the present study, however, 
show that H.A.A. persistence in these patients is probably not the result of gross deficiency in the host immune response.

The authors acknowledge the technical help of Miss Praful Damani and the help of Steven Lwanga with statistics. Dr. John Ziegler provided valuable help in the preparation of the text.

This work is supported by contract No. PH43-67-1343 from the

National Cancer Institutes, Bethesda, Maryland, U.S.A.

Requests for reprints should be addressed to: Dr. Aron Primack, N.C.I.-V.A. Oncology Unit, V.A. Hospital, 50 Irving Street N.W., Washington, D.C., 20422, U.S.A.

\section{References}

Alpert, E., and Isselbacher, K. J. (1971). Lancet, 2, 1087.

Anand, S, and Malaviya, A. N. (1971). Lancet, 2, 1032

Agarwaal, S. S., et al. (1970). Fournal of Clinical Investigation, 49, 161

Bagshawe, A. F., Parker, A. M., and Jindani, A. (1971). British Medical fournal, 1,88

Blumberg, B. S., Friedlaender, J. S., Woodside, A., and Sutnick, A. I. (1969). Proceedings of the National Academy of Sciences of the U.S.A., 62, 1108. Bluming, A. Z., Vogel, C. L., Ziegler, J. L., Mody, N., and Kamya, G. (1972). Annals of Internal Medicine, 76, 405.

Brown, R. B., et al. (1967). Annals of Internal Medicine, 1967, 67, 291.

Denison, E. K., Peters, R. L., and Reynolds, T. B. (1971). Annals of Internal Medicine, 74, 391 .

Fahey, J. L., and McKelvey, E. M. (1965). fournal of Immunology, 94, 84.
Gocke, D. J., and Howe, C. (1970). Fournal of Immunology, 104, 1031. Grabar, A. (1958). Advances in Protein Chemistry, 13, 1.

Hadziyannis, S. J., Merikas, G. E., and Afroudakis, A. P. (1970). Lancet, 2, 100.

Miller, D. G. (1962). Annals of Internal Medicine, 57, 703.

Okochi, K., and Murakami, S. (1968). Vox Sanguinis, 15, 374.

Peterson, M. R., Barker, L. F., and Schade, D. Vox Sanguinis. In press.

Prince, A. M., LeBlanc, L., Krohn, K. Masseyeff, R., and Alpert, M. E. (1970). Lancet, 2, 717.

Sherlock, S., Niazi, S. P., Fox, R. A., and Scheuer, P. J. (1970). Lancet, 1,1243 .

Shulman, N. R., and Barker, L. F. (1969). Science, 165, 300

Smith, J. B., and Blumberg, B. S. (1969). Lancet, 2, 953.

Sutnick, A. I., London, W. T., and Blumberg, B. S. (1969). Archives of Internal Medicine, 124, 722 .

Sutnick, A. I., et al. (1970). Fournal of the National Cancer Institute, 44, 1241.

Terés, J., Guardia, J., Bruguera, M., and Rodes, J. (1971). Lancet, 2, 215.

Tong, M. J., et al. (1971). Annals of Internal Medicine, 75, 687

Vogel, C. L., Anthony, P. P., Mody, N., and Barker, L. F. (1970). Lancet, 2 , 621 .

Vogel, C. L., Anthony, P. P., Sadikali, F., Barker, L. F., and Peterson, M. R. (1972). Fournal of the National Cancer Institute, $47,1583$.

Vogel, C. L., and Linsell, C. A. (1972). Fournal of the National Cancer Institute, 48, 567.

Vyas, G. N., and Shulman, N. R. (1970). Science, 170, 33.

Waldorf, D. S., Sheagren, J. N., Trautman, J. R., and Block, J. B. (1966). Lancet, 2, 773 .

Welsh, J. D., et al. (1972). Lancet, 1, 592.

Wilson, W. E. C., Kirkpatrick, C. H., and Talmage, D. W. (1965). Annals of Internal Medicine, 62,

Wright, G. G., and Feinberg, R. J. (1952). Fournal of Immunology, 68, 65.

Wright, R., McCollum, R. W., and Klatskin, G. (1969). Lancet, 2, 117.

Ziegler, J. L., Lewis, M. G., Luyombya, J. M. S., and Kiryabwire, J. W. M. (1969). British fournal of Cancer, 23, 729.

\section{Coagulation Changes during Termination of Pregnancy by Prostaglandins and by Vacuum Aspiration}

Nuffield Department of Obstetrics and Gynaecology, John Radclifie Hospital, Oxford OX3 9DU

M. H. H. BADRAOUI, M.B., M.S., Clinical demonstrator (Present address: Department of Obstetrics and Gynaecology, Faculty of Medicine, Ai Azhar University, Cairo, Egypt)

JOHN BONNAR, M.D., F.R.C.O.G., First Assistant

KEITH HILLIER, B.SC., PH.D., Research Officer

M. P. EMBREY, M.D., F.R.C.o.G., First Assistant known about changes in blood coagulation during termination of pregnancy.

After intra-amniotic injection of hypertonic saline to induce mid-trimester abortion, changes in coagulation factors have been reported which are consistent with disseminated intravascular coagulation (Stander et al., 1971). In view of this we investigated the coagulation system during induction of midtrimester abortion with prostaglandin $\mathrm{F}_{2} \alpha$ and the termination of pregnancy in the first trimester by vacuum aspiration.

\section{Patients and Methods}

Twelve patients were studied aged 18 to 37 years (mean 23 years) and parity one to seven, having termination of pregnancy at 14 to 20 weeks' gestation (mean 17 weeks) by extra-amniotic prostaglandin $\mathrm{F}_{2} \alpha$. Eleven patients were studied aged 18 to 39 years (mean 24 years) and parity one to four, having termination of their pregnancies by vacuum aspiration at eight to 12 weeks' gestation (mean 10 weeks).

Termination by Extra-amniotic Prostaglandin $F_{2} \alpha_{0}-\mathrm{A}$ Foley catheter was inserted through the cervix into the extra-amniotic space and the bulb was inflated with $40 \mathrm{ml}$ of distilled water. A test dose of $250 \mu \mathrm{g}$ of prostaglandin $\mathrm{F}_{2} \alpha$ was injected into the extra-amniotic space via the Foley catheter. If no side effects occurred $750 \mu \mathrm{g}$ was instilled at two-hourly intervals until abortion took place. Samples of venous blood $(18 \mathrm{ml})$ were withdrawn into a plastic syringe at the following stages: 1 , before administration of prostaglandin $\mathrm{F}_{2} \alpha ; 2$, when uterine contractions were established two to four hours after the first instillation of prostaglandin, 3; immediately after the expulsion of the products of conception; and 4, twenty-four hours after abortion.

Termination by Vacuum Aspiration.-This operation was carried out under general anaesthesia by using a Karman suction curette. Venous blood samples $(18 \mathrm{ml})$ were withdrawn 